\title{
Laparoscopic Heminephroureterectomy in Infants Weighing Less Than 10 Kilograms: The Two Peculiar Cases
}

\author{
Marianna laquinto ${ }^{1}$, Maria-Grazia Scarpa ${ }^{2}$, Roberto De Castro ${ }^{3}$, Daniela Codrich ${ }^{4}$, Edoardo Guida ${ }^{5}$, Alessia Cerrina ${ }^{6}$, \\ Federica Pederiva ${ }^{7}$, Maria A Lembo ${ }^{8}$, Jurgen Schleef ${ }^{9}$
}

\begin{abstract}
Aim: We report two peculiar cases of laparoscopic heminephrectomy in infants weighing less than $10 \mathrm{~kg}$ with megaureter of nonfunctioning renal upper pole.

Cases description: A 6-month-old boy, with history of upper pole pyo-hydroureteronephrosis managed by percutaneous nephrostomy, was affected in the left side; while a 17-month-old girl, with history of abdominal mass then proved to be a giant megaureter of nonfunctioning renal upper pole, was affected in the right side and she was previously treated for primitive obstructive megaureter (in the lower pole). Laparoscopic heminephroureterectomy with a transperitoneal approach was performed. Mean length of surgery was 160 minutes. We reported no conversion to open surgery neither intraoperative bleeding/urine leakage. Mean hospitalization duration was 5 days. The reoperation rate was $0 \%$. In both cases at preliminary follow-up, we reported a good outcome.

Conclusion: Laparoscopic heminephrectomy is considered a technically challenging procedure, especially for small infant but, according to our experience, it is safe and effective if performed in pediatric centers with high experience in minimally invasive surgery.

Keywords: Heminephrectomy, Infant weighing less than $10 \mathrm{~kg}$, Laparoscopy, Megaureter.

World Journal of Laparoscopic Surgery (2020): 10.5005/jp-journals-10033-1410
\end{abstract}

\section{BACKGROUND}

Nowadays, minimally invasive surgery (MIS) is increasingly used, compared to open procedures, especially in pediatric urology. ${ }^{1-4}$ Nevertheless, few reports exist regarding the experience in infants under 2 years old or weighing less than $10 \mathrm{~kg}$, particularly at risk of conversion and/or complications. ${ }^{5-9}$ We report two peculiar cases of laparoscopic heminephroureterectomy in infants of this risk group with megaureter of nonfunctioning renal upper pole.

\section{Case Descriptions}

\section{Case 1}

A male infant with prenatal diagnosis of moderate left hydroureteronephrosis and suspicion the of duplex renal system (DRS). At birth, the echography confirmed the presence of left DRS with upper pole (UP) hydroureteronephrosis; he was followed by nephrologists with ultrasound (US) controls, always stables, and voiding cystourethrography (VCUG) at 4-month-old, showing the absence of vesicoureteral reflux (VUR). He was asymptomatic until the age of 5 months, when he came to the hospital emergency with high fever and inappetence. Left UP pyohydroureteronephrosis was diagnosed (Fig. 1), managed by percutaneous nephrostomy placement and intravenous antibiotic therapy. During the recovery, a descending pyelography was performed by the nephrostomy that showed no passage of contrast into the bladder (Fig. 2). After 1 month, a dynamic renal scan (Mag3) was performed: bilateral DRS with ectopic megaureter (MU) in left nonfunctioning UP was described.

\section{Case 2}

A female infant with prenatal diagnosis of severe right hydroureteronephrosis, confirmed at birth. Voiding cystourethrography excluded VUR and dynamic renal scan (Mag3)
1,2,4-9 Department of Urologic and Pediatric Surgery, Burlo Garofolo Children's Hospital, Trieste, Friuli Venezia Giulia, Italy

${ }^{3}$ Department of Urologic and Pediatric Surgery, Prof Petrucciani Clinic, Lecce, Italy

Corresponding Author: Marianna laquinto, Department of Urologic and Pediatric Surgery, Burlo Garofolo Children's Hospital, Trieste, Friuli Venezia Giulia, Italy, Phone: +34 594747401, e-mail: i.marianna@ hotmail.it

How to cite this article: laquinto $M$, Scarpa M-G, De Castro $R$, et al. Laparoscopic Heminephroureterectomy in Infants Weighing Less Than 10 Kilograms: The Two Peculiar Cases. World J Lap Surg 2020;13(2):80-83. Source of support: Nil

Conflict of interest: None

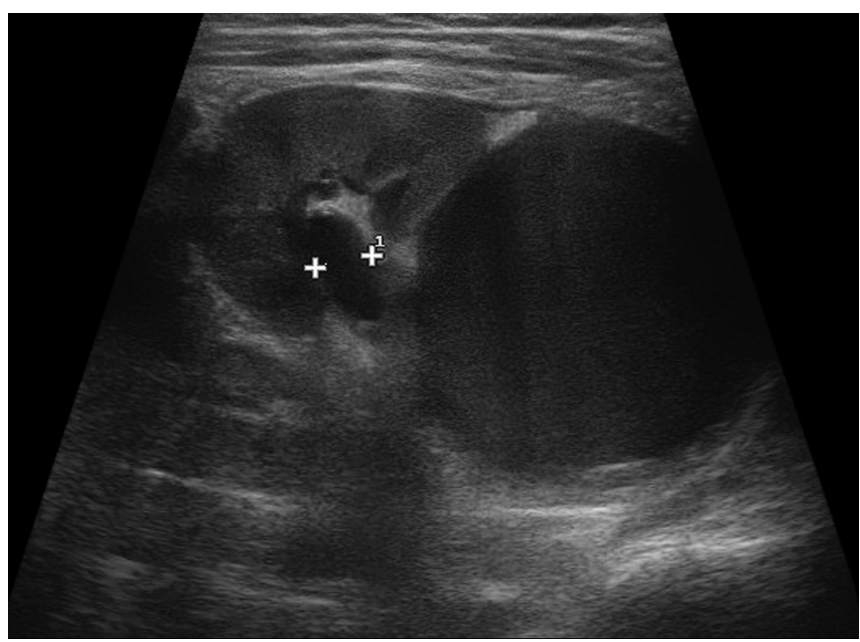

Fig. 1: Ultrasound view when the left upper pole pyohydroureteronephrosis was diagnosed in Case 1

C) The Author(s). 2020 Open Access This article is distributed under the terms of the Creative Commons Attribution 4.0 International License (https://creativecommons. org/licenses/by-nc/4.0/), which permits unrestricted use, distribution, and non-commercial reproduction in any medium, provided you give appropriate credit to the original author(s) and the source, provide a link to the Creative Commons license, and indicate if changes were made. The Creative Commons Public Domain Dedication waiver (http://creativecommons.org/publicdomain/zero/1.0/) applies to the data made available in this article, unless otherwise stated. 


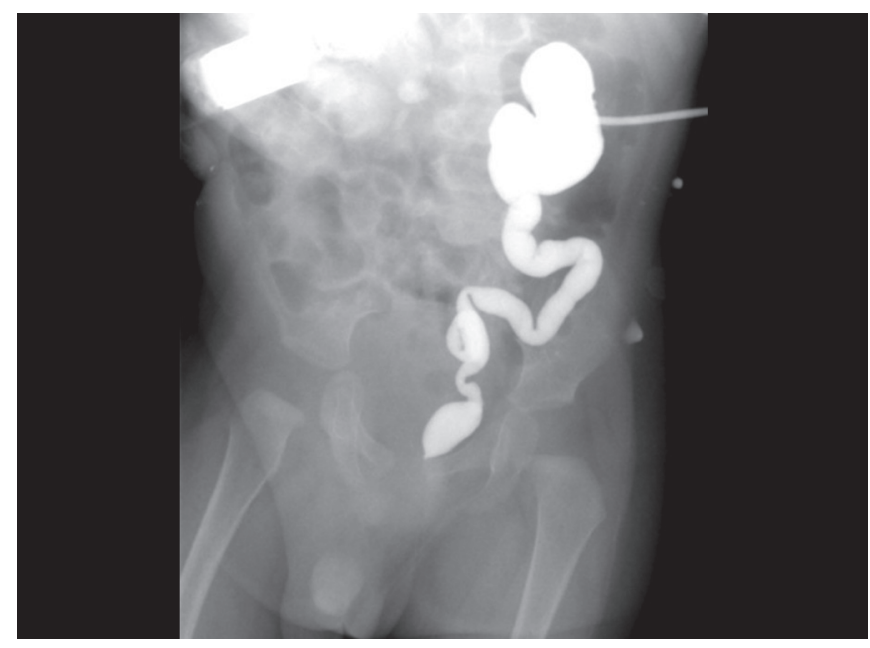

Fig. 2: Descending pyelography, performed by the nephrostomy in the Case 1, showed no passage of contrast into the bladder

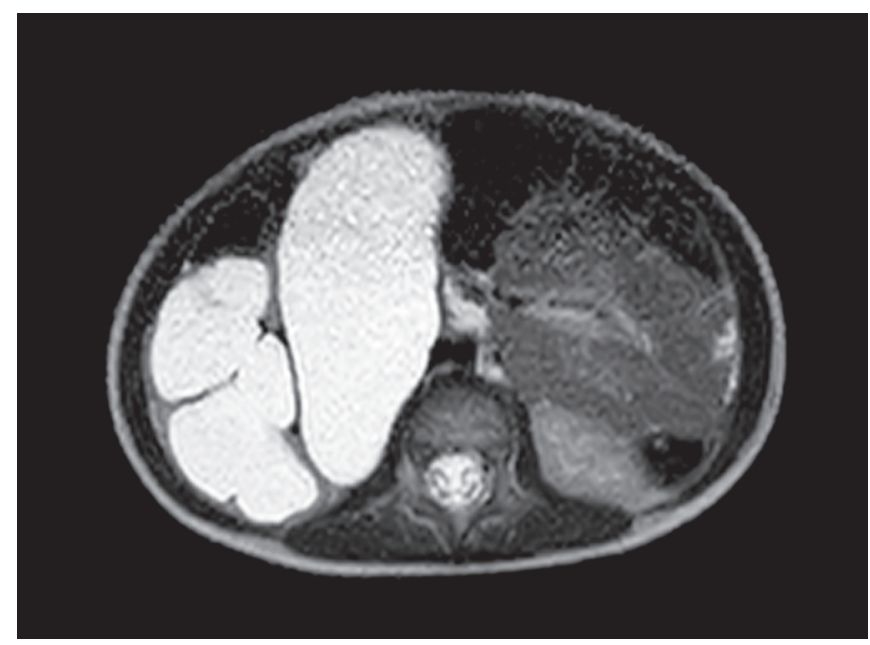

Fig. 4: In Case 2, the uro-magnetic resonance imaging showed a giant megaureter (with a maximum diameter of $5 \mathrm{~cm}$ ) of a renal nonfunctioning inner pole

underlined right primitive obstructive megaureter (POM). Given the progressive hydroureteronephrosis, when she was 4-monthold, a double J stent was put in a single right ureteral orifice. The US controls showed an insufficient drainage of the urinary tract by the $\mathrm{J} J$ stent, in a patient with respiratory distress. We performed a right ureterostomy, with a good outcome. At 11 months of age, ureteral right reimplantation was performed (Cohen procedure). Because of persistent hydronephrosis at US controls, associated with a palpable masse, in an asymptomatic patient, an ascending pyelography was performed, showing a good outcome of the POM and no communication with the mass. An extrarenal cystic mass, in particular a cystic lymphangioma, was suspected. Finally, uromagnetic resonance imaging (uro-MRI) showed a giant MU (with a maximum diameter of $5 \mathrm{~cm}$ ) of a renal nonfunctioning UP (Figs 3 and 4) - doubt about an incomplete DRS or ectopic giant MU.

The patients underwent heminephroureterectomy for their upper urinary tract duplication anomaly (Case 1: 6-month-old-8 kg; Case 2: 17-month-old-9.8 kg).

In both patients, the procedure started with a retrograde endoscopic LP ureteral catheterization, followed by a transperitoneal

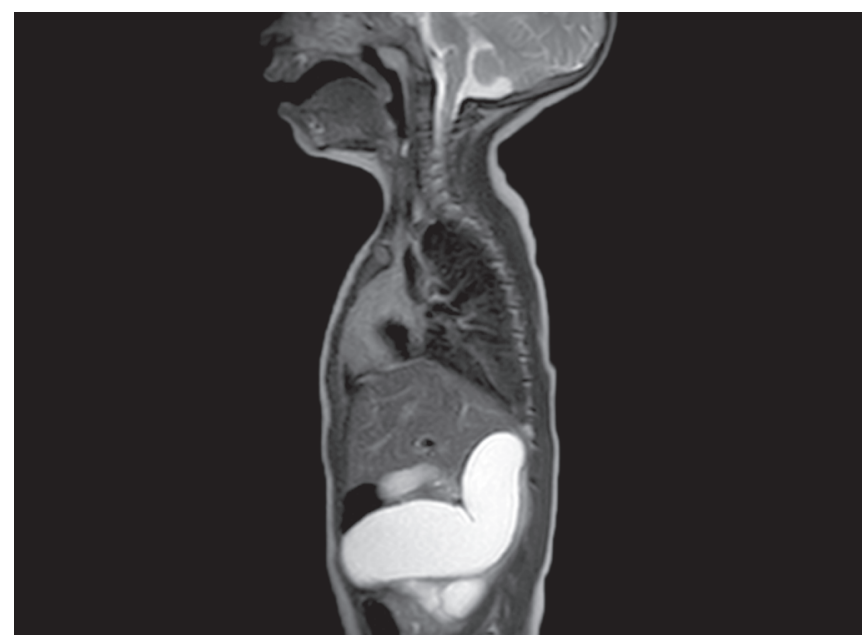

Fig. 3: In Case 2, the uro-magnetic resonance imaging showed a giant megaureter (with a maximum diameter of $5 \mathrm{~cm}$ ) of a renal nonfunctioning upper pole

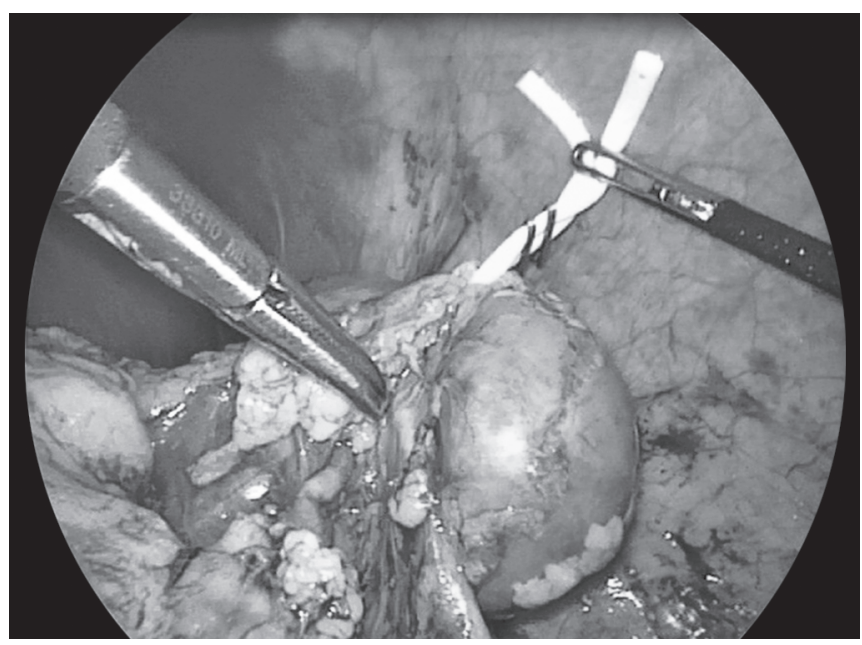

Fig. 5: Intraoperative view of the renal lower pole hilum isolation and preparation for passing behind it the upper pole megaureter

approach in a semilateral decubitus. Four trocars for the right side were used, while three for the left side, with a $10 \mathrm{~mm} / 30^{\circ}$ laparoscope and $\mathrm{CO}_{2}$ insufflation at a maximum pressure of 8-10 $\mathrm{mm} \mathrm{Hg}$. The ipsilateral colonic flexure was mobilized, thus exposing Gerota's fascia. The UP ureter was identified, freed from the lower ureter without compromising his blood supply and dissected distally as far as possible, achieving a nearly complete ureterectomy. It was then passed behind the renal hilum; this step is technically the most difficult part of the procedure and often time-consuming. The UP vessels were ligated by clips, only after identifying the blood vessels to both renal systems (Fig. 5). The last step consisted to transect the renal UP parenchyma following demarcation resulting by the vascular ligation (Fig. 6). We used a special hemostatic device (LigaSure) for dissection and parenchymal section. Finally, we removed the specimen through the $10 \mathrm{~mm}$ umbilicus port and we have not left an abdominal drain.

In Case 1, despite the numerous adhesions due to the UP pyohydroureteronephrosis, the MU and the hypoplastic UP were successfully removed. The ectopic MU was isolated as far down as possible and ligated with Endoloop, leaving an ureteral stump of 


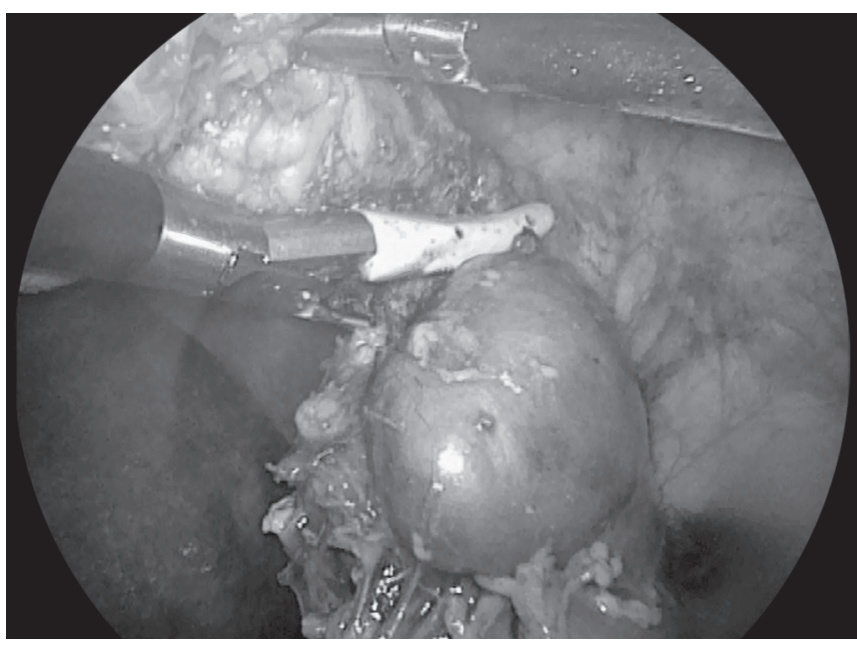

Fig. 6: Intraoperative view of the upper pole renal parenchyma transection, following the demarcation after vascular control

about $3 \mathrm{~cm}$. In Case 2, the giant MU of an incomplete DRS, severely compressing the LP pelvis and very adherent to the twin ureter and the adjacent structures, was completely removed with the hypoplastic UP.

Mean length of surgery was 160 minutes, including cystoscopy. We reported no conversion to open surgery neither intraoperative bleeding/urine leakage. Postoperative analgesia included paracetamol every 6-8 hours and Ketorolac as needed. The Foley catheter was removed on postoperative day 2. We had a minor complication (fever) in Case 1, with no effect on the outcome. Mean hospitalization was 5 days. In both cases at preliminary follow-up (mean 9 months), we reported a good outcome with normal US controls and no loss of renal function on the residual kidney moiety.

\section{Discussion}

Duplex renal system is one of the most common congenital renal tract abnormalities. The majority of cases are clinically silent or diagnosed incidentally during imaging studies and no treatment is necessary. While, if DRS is associated with VUR, ectopic ureter, ureterocele, ureteral obstruction, and symptoms occur (hydronephrosis, UTI, incontinence), a surgical treatment might be necessary. ${ }^{4,10-12}$ In 1993, Jordan and Winslow successfully carried out the first laparoscopic transperitoneal (TP) heminephrectomy in a 14-year-old child. ${ }^{13}$ Thereafter, this approach, compared with open surgery, became very popular in pediatric urology, reporting less postoperative pain, shorter hospitalization time, better cosmetic effect, and faster return to full physical activity in the child. ${ }^{12,14-16}$

In the same year, 1993, the first laparoscopic urological procedure in a small infant (8-month-old) was described by Koyle et al. They concluded that the laparoscopic approach in this specific group of patients is feasible and reproducible; however, it is a challenging procedure with a higher incidence of morbidity. ${ }^{2}$

Laparoscopy in small infants requires special care and has a steep learning curve. It is highly important for conversion rate and its potentiality to develop complications (nonspecific laparoscopic complications, attributable to the insufflation of gas or due to instruments, and specific surgical complications). ${ }^{17,18}$ In particular, laparoscopic heminephrectomy is more technically difficult and requires more experience compared with the nephrectomy due to the likelihood of complications such as hematoma, urinoma, and the risk of the residual pole pedicle injury. ${ }^{12,19,20}$

Laparoscopic heminephrectomy can be performed with transperitoneal, lateral, or posterior retroperitoneoscopic approaches. ${ }^{6,14,21}$ In addition, robot-assisted approach is reported in the literature. ${ }^{11}$

The limited working space and, consequently, the peritoneal tear risk are the main disadvantages of a retroperitoneal approach. ${ }^{6}$ Wallis et al. described a $15.4 \%$ conversion rate and $40 \%$ of functional loss on the residual kidney moiety after retroperitoneal heminephrectomy. Therefore, they supported the use of open procedures in children under 1 year. ${ }^{5}$ Castellan et al. reported that $80 \%$ of all complications occurred in patients under 1 year, with a $12.5 \%$ conversion rate, so they recommended the TP approach in this group of patients. ${ }^{6}$ Miranda et al. described a series of seven TP heminephrectomies, without complications, in children under 2 years. ${ }^{22}$ Leclair et al. reported in $21 \%$ of the patients, using retroperitoneal approach, conversion to open surgery, significantly related with the patient's young age. ${ }^{16}$

The advantages of using the TP laparoscopic approach include achieving larger working space with excellent renal exposure and easier access to the upper pole. ${ }^{23,24}$ Also, this approach allows the surgeon to perform a complete ureterectomy when needed.

In our cases, we performed heminephrectomies transperitoneally, first of all for patients' age and weight, and also because of the history of infection (UP pyohydroureteronephrosis) in Case 1 and the huge MU in Case 2.

Laparoscopic heminephrectomy is usually carried out with three or four ports. ${ }^{12,19,23,25,26}$ It is useful to insert the fourth trocar on the right side for the liver retraction and for better exposure of the renal upper pole. For untrained pediatric urologists, the use of four ports in laparoscopic heminephrectomies was recommended for both right and left sides. ${ }^{12}$ We used four trocars for the right side and three trocars for the left one.

Intraabdominal organ injuries and adhesion formation are the major risks of the TP approach, related to bowel mobilization. ${ }^{3}$ However, we reported no digestive postoperative complications.

Some authors, to verify the integrity of the parenchymal resection edge and the possibility of urine leakage, inject methylene blue dye into the catheter positioned in the ureter of the normal functioning moiety. In our cases, we did not consider it necessary, given the excellent view of renal demarcation after vascular control.

In our technique, using a special device (LigaSure) has proven to be an effective aid to make a delicate dissection and parenchymal section.

According to us, more studies are necessary, in the near future, to evaluate the outcomes of minimally invasive surgery (MIS) among neonates and small infants and, for them, laparoscopy should be considered an additional alternative in hands of expert pediatric surgeons able to manage every complication, if needed.

\section{Conclusion}

Minimally invasive urological procedures in neonates and small infants are technically challenging, requiring patient special care and surgeon expertise. However, based on our experience, we validate that such procedures can be safely performed with good outcomes and the TP approach is the most indicate to reduce the conversion and complication rate in this group of patients. 


\section{References}

1. Robinson BC, Snow BW, Cartwright PC, et al. Comparison of laparoscopic vs open partial nephrectomy in a pediatric series. J Urol 2003;169(2):638-640. DOI: 10.1016/S0022-5347(05)63980-8.

2. Koyle MA, Woo HH, Kavoussi LR. Laparoscopic nephrectomy in the first year of life. J Pediatr Surg 1993;28(5):693-695. DOI: 10.1016/00223468(93)90034-I.

3. Moore RG, Kavoussi LR, Bloom DA, et al. Pediatric urology: postoperative adhesion formation after urological laparoscopy in the pediatric population. J Urol 1995;153(3 Pt 1):792-795. DOI: 10.1097/00005392-199503000-00076.

4. Yao D, Poppas DP. A clinical series of laparoscopic nephrectomy, nephroureterectomy and heminephroureterectomy in the pediatric population. J Urol 2000;163(5):1531-1535. DOI: 10.1016/S00225347(05)67672-0.

5. Wallis $M C$, Khoury $A E$, Lorenzo AJ, et al. Outcome analysis of retroperitoneal laparoscopic heminephrectomy in children. J Urol 2006;175(6):2277-2280. DOI: 10.1016/S0022-5347(06)00338-7.

6. Castellan M, Gosalbez R, Carmack AJ, et al. Transperitoneal and retroperitoneal laparoscopic heminephrectomy-what approach for which patient? J Urol 2006;176(6 Pt 1):2636-2639. DOI: 10.1016/ j.juro.2006.08.053.

7. Sydorak RM, Shaul DB. Laparoscopic partial nephrectomy in infants and toddlers. J Pediatr Surg 2005;40(12):1945-1947. DOI: 10.1016/ j.jpedsurg.2005.08.013.

8. Mulholland TL, Kropp BP, Wong C. Laparoscopic renal surgery in infants $10 \mathrm{~kg}$ or less. J Endourol 2005;19(3):397-400. DOI: 10.1089/ end.2005.19.397.

9. Schneider A, Ripepi M, Henry-Florence C, et al. Laparoscopic transperitoneal partial nephrectomy in children under 2 years old: a single-centre experience. J Pediatr Urol 2010;6(2):166-170. DOI: 10.1016/j.jpurol.2009.06.012.

10. Aydogdu I, Silay MS. Transperitoneal laparoscopic heminephroureterectomy in the pediatric population: a single-centre experience using a sealing device. Can Urol Assoc J 2018;12(9): 409-414. DOI: 10.5489/cuaj.4992.

11. Kapoor V, Elder JS. Simultaneous bilateral robotic-assisted laparoscopic procedures in children. J Robot Surg 2015;9(4):285-290. DOI: 10.1007/s11701-015-0528-x.

12. Esposito C, Varlet F, Patkowski D, et al. Laparoscopic partial nephrectomy in duplex kidneys in infants and children: results of an european multicentric survey. Surg Endosc 2015;29(12):3469-3476. DOI: 10.1007/s00464-015-4096-y.

13. Jordan $\mathrm{GH}$, Winslow BH. Laparoendoscopic upper pole partial nephrectomy with ureterectomy. J Urol 1993;150(3):940-943. DOl: 10.1016/S0022-5347(17)35656-2.
14. Nerli RB, Vernekar R, Guntaka AK, et al. Laparoscopic hemi/partial nephrectomy in children with ureteral duplication anomalies. Pediatr Surg Int 2011;27(7):769-774. DOI: 10.1007/s00383-011-2883-7.

15. Piaggio L, Franc-Guimond J, Figueroa TE, et al. Comparison of laparoscopic and open partial nephrectomy for duplication anomalies in children. J Urol 2006;175(6):2269-2273. DOI: 10.1016/ S0022-5347(06)00342-9.

16. Leclair MD, Vidal I, Suply E, et al. Retroperitoneal laparoscopic heminephrectomy in duplex kidney in infants and children: a 15-year experience. Eur Urol 2009;56(2):385-389. DOI: 10.1016/ j.eururo.2008.07.015.

17. Eshtewi SA. Laparoscopy complications in neonates and small infants. World J Laparosc Surg 2008;1(2):15-19. DOI: 10.5005/ jp-journals-10007-1052.

18. Iwanaka $T$, Uchida $H$, Kawashima $H$, et al. Complications of laparoscopic surgery in neonates and small infants. J Pediatr Surg 2008;39(12):1838-1841. DOI: 10.1016/j.jpedsurg.2004.08.011.

19. You D, Bang JK, Shim M, et al. Analysis of the late outcome of laparoscopic heminephrectomy in children with duplex kidneys. BJU Int 2010;106(2):250-254. DOI: 10.1111/j.1464-410X.2009. 09038.x.

20. Valla JS, Breaud J, Carfagna L, et al. Treatment of ureterocele on duplex ureter: upper pole nephrectomy by retroperitoneoscopy in children based on a series of 24 cases. Eur Urol 2003;43(4):426-429. DOI: $10.1016 / \mathrm{S} 0302-2838(03) 00043-5$.

21. Metzelder ML, Kübler JF, Nustede R, et al. LigaSure in laparoscopic transperitoneal heminephroureterectomy in children: a comparative study. J Laparoendosc Adv Surg Tech A 2006;16(5):522-525. DOI: 10.1089/lap.2006.16.522.

22. Miranda ML, Oliveira-Filho AG, Carvalho PT, et al. Laparoscopic upperpole nephroureterectomy in infants. Int Braz J Urol 2007;33(1):87-91. DOI: 10.1590/S1677-55382007000100015.

23. Gundeti MS, Patel Y, Duffy PG, et al. An initial experience of 100 paediatric laparoscopic nephrectomies with transperitoneal or posterior prone retroperitoneoscopic approach. Pediatr Surg Int 2007;23(3):795-799. DOI: 10.1007/s00383-007-1941-7.

24. Mahomed AA, Hoare C, Welsh F, et al. A two-centre experience with the exclusive use of laparoscopic transperitoneal nephrectomy for benign renal disease in children. Surg Endosc 2007;21(9):1532-1536. DOI: 10.1007/s00464-006-9162-z.

25. Gozen AS, Badawy H, Teber D, et al. Outcome of laparoscopic upper pole heminephroureterectomy in children: a two-centre experience. Arab J Urol 2016;14(4):287-291. DOI: 10.1016/j.aju.2016.08.006.

26. Kim C, McKay K, Docimo SG. Laparoscopic nephrectomy in children: systematic review of transperitoneal and retroperitoneal approaches. Urology 2009;73(2):280-284. DOI: 10.1016/j.urology.2008. 08.471 . 